Int. J. Dev. Biol. 54: 585-589 (2010)

doi: $10.1387 / \mathrm{ijdb} .082786 \mathrm{zc}$

\title{
Intraovarian transplantation of stage I-II follicles results in viable zebrafish embryos
}

\author{
ZSOLT CSENKI ${ }^{1}$, ANDREAS ZAUCKER 2,3 , BALÁZS KOVÁCS ${ }^{4}$, YAVOR HADZHIEV2,3 ÁRPÁD HEGYI" \\ KATALIN-KINGA LEFLER ${ }^{1}$, TAMÁS MÜLLER ${ }^{1}$, RÓBERT KOVÁCS ${ }^{1}$, BÉLA URBÁNYI*,1, LÁSZLÓ VÁRADI*,1 \\ and FERENC MÜLLER ${ }^{*, 2,3}$

\begin{abstract}
${ }^{1}$ Department of Fish Culture, Institute of Environmental and Landscape Management, Faculty of Agricultural and Environmental Sciences, Szent István University, Gödöllo, Hungary, ${ }^{2}$ Institute of Toxicology and Genetics, Forschungszentrum Karlsruhe, Eggenstein-Leopoldshafen, Germany, ${ }^{3}$ Department of Medical and Molecular Genetics, Division of Reproductive and Child Health, Medical School, University of Birmingham, UK and ${ }^{4}$ Regional University Center of Excellence in Environmental Industry Based on Natural Resources, Szent István University Gödöllo, Hungary
\end{abstract}

\begin{abstract}
Maternal gene products drive early embryogenesis almost exclusively until the mid blastula transition (MBT) in many animal models including fish. However, the maternal contribution to embryogenesis does not stop at MBT, but continues to be an essential regulator of key developmental processes. The extent to which maternal effects contribute to embryonic and larval development is hard to estimate due to the technical difficulty of interfering with maternal gene products by conventional forward and reverse genetic tools. Therefore, novel methods to manipulate maternal factors in oocytes need to be developed. Here, we provide a proof of principle protocol for transplanting stage I-II zebrafish follicles into recipient mothers where donor stage I oocytes can develop to stage IV in 2 weeks and in 3 weeks they develop into mature eggs and produce viable offspring. Moreover, we show that simple microinjection of stage I-II follicles with RNA results in reporter gene expression in oocytes and paves the way for developing tools for interfering with maternal gene activity. This early stage oocyte transplantation protocol provides a means to study cellular and molecular aspects of oocyte development in the zebrafish.
\end{abstract}

KEY WORDS: oogenesis, follicle, transplantation, transgenic, maternal effect

\section{Introduction}

In anamniotes, including fishes, RNA and proteins deposited in the egg before fertilization drive early embryogenesis until the mid blastula transition (MBT) (Kane and Kimmel, 1993). However, maternal contribution to embryogenesis does not stop at MBT, but continues to be an essential regulator of key developmental processes including early embryogenesis (Dosch et al., 2004), reviewed in (Pelegri, 2003)). Maternal effect gene products continue to contribute to larval development at late organogenesis stages (Ryu et al., 2005). While thousands of genes are expressed maternally (Mathavan et al., 2005) the genetic and molecular mechanisms of maternal effects remain little understood.

The technologies to manipulate maternal gene function such as forward genetic screens (reviewed in Pelegri et al., 2004) are laborious and time consuming while phenotypic rescue of zygotic mutants by wild type mRNA injection (Gritsman et al., 1999) and the germ line replacement method (Ciruna et al., 2002) are limited to genes for which zygotic mutants are available. Given the very limited information on the genetic mechanisms of oogenesis and maternal effect in development, and the difficulty to manipulate the genes involved in these processes, the development of new approaches to manipulate oocytes is needed.

Morphology development of zebrafish oocytes has been described and divided into 5 stages (Selman et al., 1993). Stage I oocytes range from 7-140 $\mu \mathrm{m}$ in diameter, are transparent with visible germinal vesicle and form follicles. Maternal genes that

\footnotetext{
Abbreviations used in this paper: bp, base pairs; chr, chromosome; CM, centimorgan; dpt, day post transplantation; F, forward; MBT, mid blastula transition; R, reverse; St, stage.
}

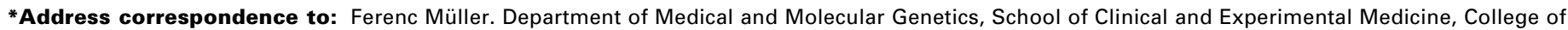

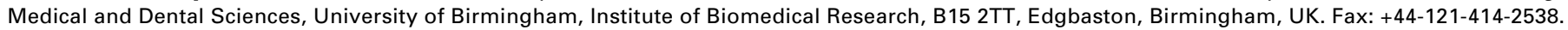
e-mail: f.mueller@bham.ac.uk or alternatively Béla Urbányi (urbanyi.bela@mkk.szie.hu) or László Váradi (varadi.laszlo@mkk.szie.hu).
}

ISSN: Online 1696-3547, Print 0214-6282 
affect embryogenesis are already expressed at this stage (Pelegri, 2003) (Gore and Sampath, 2002). In the following stage II, (140$340 \mu \mathrm{m})$ accumulation of proteins required for embryogenesis takes place. Oocyte growth and probably expression of maternal genes end at stage IV (690-730 $\mu \mathrm{m}$ (Pelegri, 2003)). While it is possible to in vitro maturate stage IV oocytes in zebrafish (Tokumoto et al., 2005), efficient interference with maternal factors requires the manipulation of stage I-II of oocyte which have not yet been succesfully induced to grow into mature eggs in vitro.

In this report our aim was to test whether it is possible to isolate, directly manipulate and induce the further development of isolated zebrafish stage I and II oocytes upon transplantation into recipient mothers with the long term goal of manipulating maternal effect gene products in oocytes.

\section{Results}

First we asked if early stage follicles of zebrafish can transplanted into recipient zebrafish females. As demonstrated in Fig. 1 B-D, recipient ovaries recovered after transplantation contained YFP positive donor oocytes while no YFP signal could be seen in control recipient ovaries, that have not been subjected to transplantation. The frequency of the retention of the injected follicles was high $(47.5 \% \pm 20.5, n=360$, Table 1$)$, reaching up to 17 follicles of 25 injected follicles in one experiment. Donor follicles were still detectable in recipient ovaries at $14 \mathrm{dpt}$ (2.6 $\pm 2.6 \%, n=350$; Table 1)

Next we asked whether oocytes in transplanted stage I and II follicles resume oogenesis. We have postulated that transplanted follicles, in which oocytes continue ontogeny are expected to grow in size indicating vitellogenesis. To test this we compared the size of follicles before transplantation to transgenic follicles recovered from recipient ovaries. Besides increase in size also the general morphology of transplanted follicles suggested normal oocyte development (Fig. 1E). Transplanted follicles could reach the size of stage III follicles within 1 week post transplantation. One follicle nearly matched the size limit for stage IV follicles 2 weeks after transplantation. Taken together, these results suggest that transplanted follicles can integrate into recipient ovaries and continue oogenesis.

Next, we tested whether mature eggs can be obtained from recipient mothers in which early stage follicles were transplanted. To this end, 10 recipient females were injected with up to 100 stage I follicles and crossed with wild type males at weekly intervals over a period of 6 weeks. In two experiments, a total of 4 embryos with YFP activity were obtained from 2 wild type recipient mothers at the $3^{\text {rd }}$ and $4^{\text {th }}$ week's crossings respectively (Fig. 2 AC) indicatingnthat these embryos were developing from fertilized eggs that originated from transplanted follicles.

To verify by an independent approach that the transgenic larvae obtained from the wild type crosses of recipient females were indeed originating from transplanted oocytes, microsatellite marker analysis was carried out to establish the genetic contribution of the parents involved in the experiments. The microsatellite analysis of 8 independent genomic loci (zebrafish genome assembly v7) clearly demonstrated that the transgenic larvae shared their genotype with the transgenic donor female and the wild type male but not with the recipient female in all loci analysed (Fig. 2D and data not shown). This result demonstrates further that the transgenic offspring were indeed developing from transplanted oocytes. The transgenic larvae developed normally. One of them was grown to a mature and fully reproductive female (data not shown), suggesting that the transplantation protocol did not impact negatively on their viability.

The ability to generate viable offspring from transplanted oocytes opens the possibility to manipulate early stage follicles by direct microinjection of nucleic acids and other reagents for the

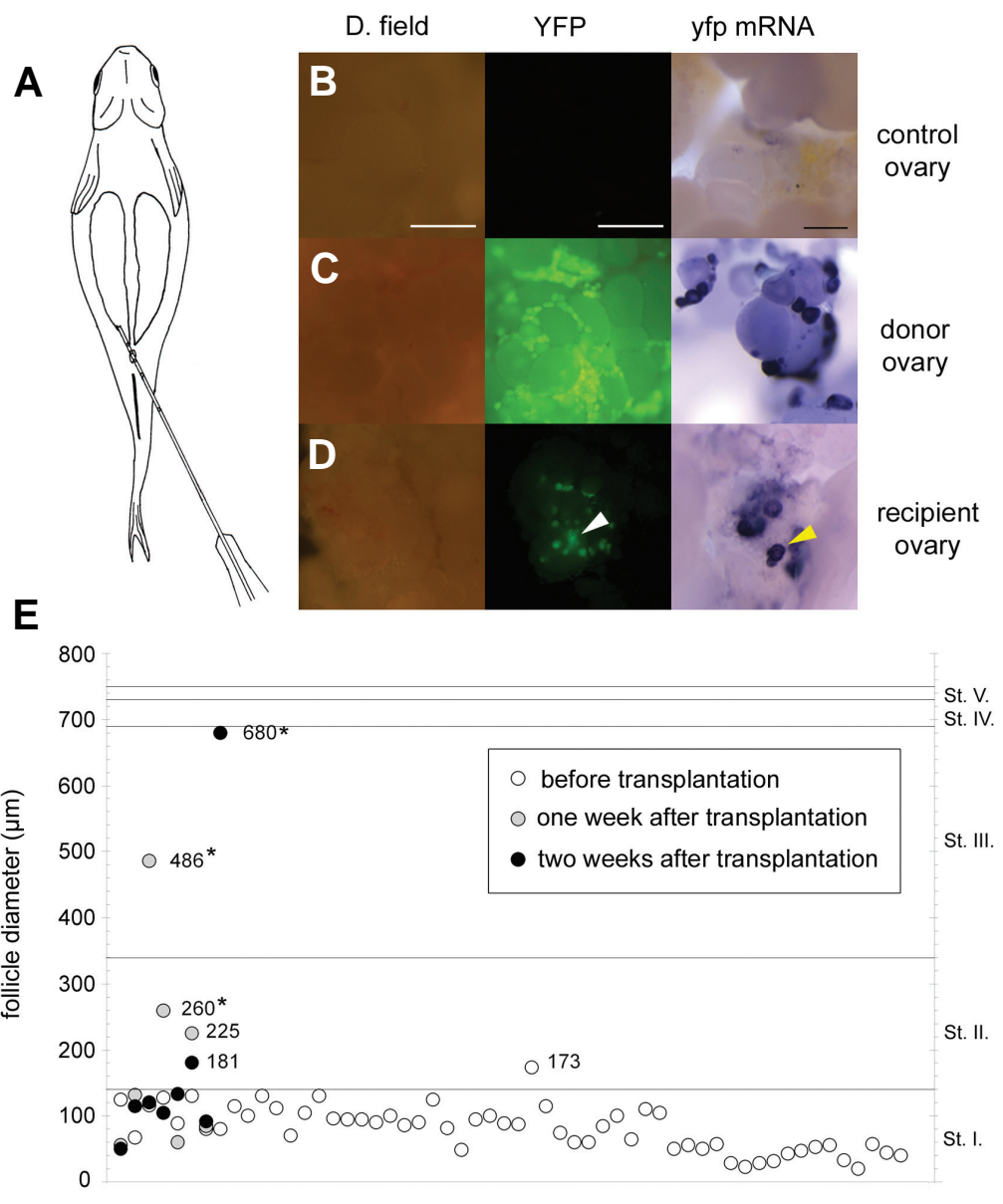

Fig. 1. Transplanted follicles invade the recipient ovary and continue oocyte development. (A), Schematic picture of the process of transplantation. (B-D) Intrauterine injection of stage I follicles results in the appearance of transplanted donor oocytes/follicles in the non-transgenic host ovary. dark field (left), YFP filter view (middle) and whole mount in situ hybridisation analysis (right) of ovaries. Transgenic donor follicles are yellowish green in GFP filter view (C) and purple in the whole mount hybridisation analysis, while no YFP signal is detected in wild type recipient ovaries without transplantation (B). (D), transplanted follicles are indicated by arrowheads among non-transgenic host follicles in a recipient ovary. (E), Size distribution of follicles (in $\mu \mathrm{m}$ ) before transplantation and after recovery from recipient ovaries. Asterisks indicate values of donor follicles recovered from recipient ovaries that are significantly different from the donor follicles measured before transplantation (Kruskal-Walis test, $P \leq 0,05$ ). Scale bar indicates $300 \mu \mathrm{m}$. 

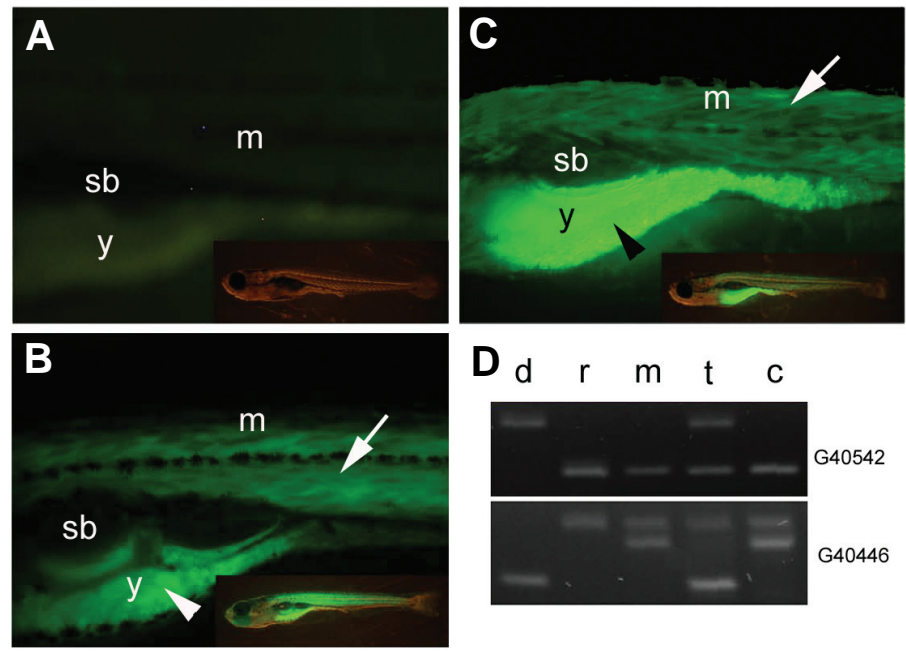

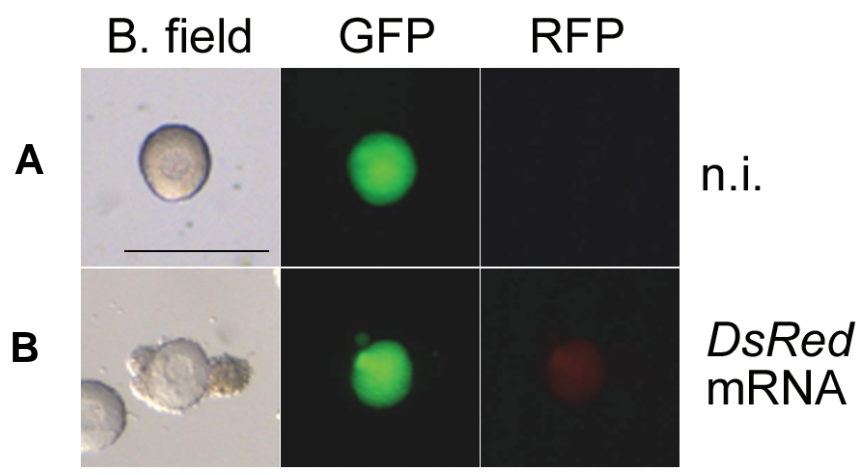

Fig. 2 (Left). Transplanted follicles develop to fertilizable eggs and produce viable offspring. (A) Non-transgenic offspring from recipient female mated with wild type male. (B) Transgenic offspring of a sibling of the donor female mated with a wild type male. (C) Transgenic offspring developing from a recipient female, which was injected with transgenic donor follicles and mated with wild type male 3 weeks after transplantation. All larvae are shown at 10 days after fertilization. Transgenic and non transgenic offspring of recipient female were analysed at 10 days post fertilization. Side view onto the trunk above the yolk ball and part of tail are shown. Fluorescence signal of the $\beta$-actin:yfp reporter construct activity is detected in the skeletal muscle and the yolk ball (arrow and arrowhead respectively). Inserts show the full view of larvae respectively. (D) Microsatellite analysis of genetic composition of donor female (d), recipient female ( $r$ ), male used for crossing with recipient female (m), offspring developing from transplanted follicle (t) and sibling from recipient female (c). The identification number of microsatellite markers are indicated on the right (for details see Table 2). Abbreviations, (sb) swim bladder, (m), muscle, (y) yolk.

Fig. 3 (Right). Microinjected stage I and stage II follicles express reporter proteins. Transgenic YFP positive non-injected (A) and DsRed $m R N A$ injected (B) follicles recovered from recipient mothers 1 day after transplantation in bright field, GFP and RFP filter views. Scale bar indicates $400 \mu \mu m$.

purpose of analysing gene function during oogenesis and maternal effect in embryogenesis. To test if such micromanipulation may be feasible in stage I and II follicles we have carried out reporter gene expression analysis in microinjected stage I and II follicles. To this end, in vitro synthesized DsRed mRNA was microinjected into the cytoplasm or the germinal vesicle of stage I and II transgenic donor oocytes. Control, non-injected transplanted follicles showed only YFP activity and no signal in the RFP filter view (Fig. 3A). In contrast, microinjected batches of transplanted YFP positive follicles included oocytes that showed

\section{TABLE 1}

\section{FREQUENCY OF RECOVERY OF TRANSPLANTED FOLLICLES IN RECIPIENT OVARIES}

\begin{tabular}{ccc} 
Day after & $\begin{array}{c}\text { No. of transplanted oocytes } \\
\text { (recipient females } \times \text { transplanted oocytes) }\end{array}$ & $\begin{array}{c}\text { Recovered oocytes } \\
\text { Mean } \pm \text { S.D. (\%) }\end{array}$ \\
\hline 1 & $8 \times 20$ & $47.5 \pm 20.5 \mathrm{a}$ \\
& $8 \times 25$ & \\
& $8 \times 25$ & $38.1 \pm 12.4 \mathrm{~b}$ \\
$5 \times 30$ & \\
& $5 \times 20$ & $20.6 \pm 16.4 \mathrm{c}$ \\
3 & $5 \times 25$ & \\
& $5 \times 30$ & $12.3 \pm 14.5 \mathrm{~d}$ \\
4 & $8 \times 25$ & $11.9 \pm 7.5 \mathrm{~d}$ \\
5 & $4 \times 30$ & \\
& $4 \times 30$ & $5.4 \pm 8.9 \mathrm{e}$ \\
6 & $6 \times 25$ & $2.3 \pm 2.7 \mathrm{f}$ \\
7 & $3 \times 30$ & \\
& $5 \times 30$ & $2.6 \pm 2.6 \mathrm{f}$ \\
\hline
\end{tabular}

Summarised data of the transplanted and recovered oocytes.

Letters indicate values that are significantly different ( $p \leq 0.05$, Kruskal-Wallis test)
DsRed activity (Fig. 3B). This result indicates that microinjected mRNA is translated into reporter protein in stage I-II oocytes. Following incubation, RFP activity was detected in $10.3 \%$ of oocytes injected with mRNA $(n=58)$. In summary, the microinjection experiments demonstrate that stage I and II oocytes can express reporter genes detectable by fluorescence microscopy upon microinjection of mRNA constructs.

\section{Discussion}

Oocyte development and its role in embryo development remain understudied in zebrafish. Novel techniques that provide insights into the cellular and molecular mechanisms involved in oocyte development are necessary preprequisite to further development in these fields of research. Important progress has been made in maturation of late stage oocytes in vitro (Seki et al., 2008), however for efficient manipulation of maternal effect gene products early stage oocytes need to be used.

In this report we provide proof of principle for a novel and simple technology to study and manipulate stage I zebrafish follicles by transplantation into recipient foster females. We provide independent lines of genetic evidence, that stage I follicles injected into the genital papilla of recipient females integrate in the recipient ovaries, can develop normally to produce viable fertilizable eggs (stage V). Furthermore, we show that stage I and II follicles can be microinjected with nucleic acids for the manipulation of gene activities. The protocol described here may form the basis of a technology to manipulate maternal gene activities in order to assess their function in oogenesis and subsequent embryonic development.

Our results provide insights into the dynamics of oocyte development. To our knowledge this report is the first experimentally 
validated description of the time dependence of oocyte development in zebrafish.

An optimised transplantation technology may have several advantages over existing methods of manipulating maternal genes in zebrafish. It allows for the direct manipulation of oocytes by gene knock down approaches and may alleviate the need for a zygotic mutant to generate a loss of function phenotype. Future work will be required however to establish knock down technologies in follicles. It is foreseeable that the efficiency of obtaining normally developing transplanted follicles needs to be improved either by targeting of the ovary during injection, improving the design of injection tools, and by screening for retention of oocytes with non invasive techniques (transparent donor strains). Importantly, immune response of the foster mother to donor follicles need to be evaluated.

Further potential applications of oocyte transplantation may include the analysis of oocyte development and time dependence of morphogenesis. Mosaic analysis of transplanted follicles in a chimeric background could provide insight into donor-host interactions. Besides developmental biology applications, oocyte transplantation (similarly to primordial germ cell transplantation (Okutsu et al., 2006)) may assist in developing tools for animal husbandry applications such as oocyte cryopreservation for rare strains / species, as well as for the in vitro reproduction of farmed fishes with problematic induction of sexual maturation (e.g. Anguillasp).

\section{Materials and Methods}

\section{Production of the transgenic fish line for labelling oocytes and collecting follicles}

The transgenic zebrafish line used for donor follicles is $\beta$ actin:yfp; uas:ache. The line was generated by co-injection of DNA fragments containing a $4.7 \mathrm{~kb}$ carp $\beta$-actinpromoter region (Alam et al., 1996, Hwang et al., 2003) linked to the yfp gene (beta-actin:YFP) and a fragment containing the zebrafish acetylcholine esterase (ache) downstream of five yeast upstream activating sequences (5xuas:achE) (Behra et al., 2002) into the $A B$ strain of zebrafish. The concentration of the fragments in the injection solution was $50 \mathrm{ng} / \mu \mathrm{l}$ and $2-5 \mathrm{nl}$ were injected per embryo. In the larval stage YFP is predominantly skeletal muscle specific, however it also shows activity in the skin and weak mosaic activity in other tissues. In adults, the transgene is broadly expressed including oocytes of all stages. Adult transgenic donor females ( $\beta$ actin:yfp) were terminally anaesthesized with MESAB $(0.4 \%$ Tricaine Methanesulfonate, $1 \%$ Na2HPO4 in 10\% Hank's solution), then ovaries were surgically removed and placed in mPBS $(2.7 \mathrm{mM} \mathrm{KCl}, 137 \mathrm{mM} \mathrm{NaCl}$, $1 \mathrm{mM} \mathrm{NaH}_{2} \mathrm{PO}_{4}, 3.2 \mathrm{mM} \mathrm{Na}_{2} \mathrm{HPO}_{4} \times 2 \mathrm{H}_{2} \mathrm{O}$ ). Ovaries were suspended and follicles were separated according to their size under a bright field stereo microscope. Stage I and II follicles in the range of 50 to $150 \mu \mathrm{m}$ diameter were collected and placed in Holtfreter's solution.

\section{Preparation and transplantation of oocytes into recipient females}

Recipient $A B$ strain females were bred on the day of the transplantation experiment. Recipients were anaesthetised by MESAB and rinsed two times in Holtfreter's solution by a modified pipette tip also used at transplantation. For transplantation of follicles a blunted glass capillary was prepared (length 7-8 cm, external diameter $1.2 \mathrm{~mm}$, internal diameter $0.65 \mathrm{~mm})$ and attached to a trimmed plastic pipette tip $(200 \mu \mathrm{l})$ over flame. The glass capillary was inserted 5-8 $\mathrm{mm}$ deep into the oviduct through the genital papilla of anaesthesized females (Fig. 1A). In the range of 25-50 follicles in a volume of $25-30 \mu \mathrm{l}$ Holtfreter solution were injected into the ovaries using the automated pipette. The females were then released to regain consciousness and kept separately for 1 day before transfer into communal tanks in a recirculation system (ZebTec, Tecniplast S.p.a., Italy). Recipient non-transgenic mothers were either used in pairwise crosses or terminally anaesthetised for surgical removal of ovaries. Size distribution of follicles before transplantation and after isolation from recipient ovaries was determined by the ImageJ program (Research Services Branch, National Institute of Mental Health, USA.)

\section{In situ hybridisation of ovaries}

The ovaries were isolated from terminally anaesthesized recipient females and were fixed overnight with BT-Fix (220 mM Sucrose, $77 \mathrm{mM}$ $\mathrm{Na}_{2} \mathrm{HPO}_{4}, 23 \mathrm{mM} \mathrm{NaH}_{2} \mathrm{PO}_{4}, 0.12 \mathrm{mM} \mathrm{CaCl}_{2}, 1.3 \mathrm{M} \mathrm{PFA}$ ) at $4^{\circ} \mathrm{C}$. Whole mount in situ hybridisation was carried out by standard protocol as described-(Hauptmann, 1999), but omitting the permeabilisation step. The $y f p$ mRNA-probe was generated by in vitro transcription of the reverse strand of the EYFP coding sequence inserted into pUT+ vector.

\section{Fluorescence microscopic analysis of oocytes and embryos and microinjection of oocytes}

DsRedmRNA was in vitrosynthesized from a $p C S 2+$.DsRed construct using the Message Machine mRNA preparation kit (Ambion, TX, USA). 10 $\mu \mathrm{l}$ injection solutions were prepared on ice at concentrations as indicated, (including $5 \mu \mathrm{l}$ of $10 \%$ phenol red and filtered, Cat\#516-8554, VWR, IL, USA) at $12000 \mathrm{rpm}$ at $4^{\circ} \mathrm{C}$. Plastic Petri dishes $(5 \mathrm{~cm}$ diameter) were coated with $2 \%$ agarose. A $2 \mathrm{~mm}$ deep groove was cut into the agarose by a scalpel in which follicles were placed. Stage I and II follicles were kept in Ringer solution (116 mM NaCl, $2.9 \mathrm{mM} \mathrm{KCl}, 1.8 \mathrm{mM} \mathrm{CaCl} 2$, and $5 \mathrm{mM}$ HEPES, pH 7.2) during injection, which was carried out by hand held femtotips (Cat\# 5242 952.008, Eppendorf Germany) attached to a microinjector (Tritech Research, USA) under a stereo microscope. RNA injected follicles were in vitro incubated for 1 day.

\section{Microsatellite analysis}

All non feeding larvae and tail fin clips from the parent individuals were

TABLE 2

\section{GENOMIC POSITION AND PRIMER DATA OF THE MICROSATELLITE MARKERS EMPLOYED}

\begin{tabular}{|c|c|c|c|c|c|c|c|c|}
\hline \multirow{2}{*}{$\begin{array}{l}\text { Marker } \\
\text { name }\end{array}$} & \multicolumn{3}{|c|}{ Genomic position } & \multirow[b]{2}{*}{ F primer } & \multirow{2}{*}{$\begin{array}{l}\text { F primer } \\
\text { length }\end{array}$} & \multirow[b]{2}{*}{ R primer } & \multirow{2}{*}{$\begin{array}{l}\text { R primer } \\
\text { length }\end{array}$} & \multirow[b]{2}{*}{ product } \\
\hline & chr & CM & bp & & & & & \\
\hline G41751 & 9 & 23,5 & 3189495 & ATTGTGCCTTGAGTGAGGCT & 20 & GAGGTGACTGCAACCGATTT & 20 & $117-251$ \\
\hline G39758 & 9 & 80,7 & 49740810 & TTGAGCTGTGAACAAGCCAC & 20 & ССТСTTCATCTGGCATCCAT & 20 & $101-159$ \\
\hline G40279 & 10 & 81,3 & 35313739 & CCGCAGTGTCAGCAGAAAT & 19 & GCGCTCTTGTTTGACCTTTC & 20 & $97-160$ \\
\hline G41760 & 11 & 36,8 & 9285133 & ACCAACCCTGAGGGAGTTTT & 20 & CCTTGCTACCGCTATGAATG & 20 & $111-149$ \\
\hline G41652 & 16 & 71,9 & 45196237 & CTGGCACTGTGGTTACCATG & 20 & AGCTGTGCTTGTGATGAACG & 20 & $131-173$ \\
\hline G40108 & 17 & 40,9 & 23397277 & ССТСТTСССАСАAGTССАТT & 20 & TTCCCAATTAAAGCAAACGC & 20 & $91-207$ \\
\hline G40542 & 18 & 64,2 & 43897912 & GAAACCCGTGAAGGTTTGAA & 20 & CTTGAACAGAGCAGAGTTCAGA & 22 & 153-217 \\
\hline G40446 & 21 & 123,7 & 43639841 & TTACTCTGTCTGCGGACACC & 20 & GCCGTGGTGCAATAGGTAGT & 20 & $80-148$ \\
\hline
\end{tabular}

Chr, chromosome, CM, centimorgan, F, forward, R, reverse, bp, base pairs 
collected and stored in ethanol at $-20^{\circ} \mathrm{C}$ until use. The fin clips were digested by Proteinase $\mathrm{K}\left(0.5 \mu \mathrm{g} / \mu \mathrm{l}, 55^{\circ} \mathrm{C}\right)$ in SET buffer $(10 \mathrm{mM} \mathrm{Tris} / \mathrm{HCl}$, $\mathrm{pH} 8.0,50 \mathrm{mM}$ EDTA, $200 \mathrm{mM} \mathrm{NaCl}$ and $0.5 \%$ SDS) in a shaker overnight, then the DNA was extracted by phenol-chloroform. The quality and the concentration of the resulting DNA was assessed by photometry (NanoPhotometer, IMPLEN, Germany). Microsatellite marker fragments were amplified by PCR using Taq polymerase and primers listed in Table 2.

\section{Acknowledgements}

The authors thank Simone Schindler, Éva Kalmár, Ákos Horváth, Tibor Béres, Éva Kovács, Endre Szabó, Elen Gócza for technical support during this work and László Orbán for critical reading of this manuscript. This work was funded by the Center of Excellence in Environmental Industry at Szent István University (RET-12/2005), the National Project for Research and Development (NKFP 4/006/2004) and the Baross Program (BAROSS-4-2005-0037), by the Hungarian National Research Fund (OTKA PD 73466), a Bolyai Research Fellowship of the Hungarian Academy of Sciences and EUTRACC project of the EU FPG programme.

\section{References}

ALAM, M.S., LAVENDER, F.L., IYENGAR, A., RAHMAN, M.A., AYAD, H.H., LATHE, R., MORLEY, S.D. and MACLEAN, N. (1996). Comparison of the activity of carp and rat beta-actin gene regulatory sequences in tilapia and rainbow trout embryos. Mol Reprod Dev 45: 117-122.

BEHRA, M., COUSIN, X., BERTRAND, C., VONESCH, J.L., BIELLMANN, D., CHATONNET, A. and STRAHLE, U. (2002). Acetylcholinesterase is required for neuronal and muscular development in the zebrafish embryo. Nat Neurosci 5: 111-118.

CIRUNA, B., WEIDINGER, G., KNAUT, H., THISSE, B., THISSE, C., RAZ, E. and SCHIER, A.F. (2002). Production of maternal-zygotic mutant zebrafish by germline replacement. Proc Nat/ Acad Sci USA 99: 14919-14924.

DOSCH, R., WAGNER, D.S., MINTZER, K.A., RUNKE, G., WIEMELT, A.P. and MULLINS, M.C. (2004). Maternal control of vertebrate development before the midblastula transition: mutants from the zebrafish I. Dev Cel/6: 771-780.

GORE, A.V. and SAMPATH, K. (2002). Localization of transcripts of the zebrafish morphogen Squint is dependent on egg activation and the microtubule cytosk- eleton. Mech Dev 112: 153-156

GRITSMAN, K., ZHANG, J., CHENG, S., HECKSCHER, E., TALBOT, W.S. and SCHIER, A.F. (1999). The EGF-CFC protein one-eyed pinhead is essential for nodal signaling. Ce//97: 121-132.

HAUPTMANN, G. (1999). Two-color detection of mRNA transcript localizations in fish and fly embryos using alkaline phosphatase and beta-galactosidase conjugated antibodies. Dev Genes Evo/209: 317-321.

HWANG, G.L., AZIZUR RAHMAN, M., ABDUL RAZAK, S., SOHM, F., FARAHMAND, H., SMITH, A., BROOKS, C. and MACLEAN, N. (2003). Isolation and characterisation of tilapia beta-actin promoter and comparison of its activity with carp beta-actin promoter. Biochim Biophys Acta 1625: 11-18.

KANE, D.A. and KIMMEL, C.B. (1993). The zebrafish midblastula transition. Development 119: 447-456.

MATHAVAN, S., LEE, S.G., MAK, A., MILLER, L.D., MURTHY, K.R., GOVINDARAJAN, K.R., TONG, Y., WU, Y.L., LAM, S.H., YANG, H. et al. (2005). Transcriptome analysis of zebrafish embryogenesis using microarrays. PLOS Genet 1: 260-276.

OKUTSU, T., YANO, A., NAGASAWA, K., SHIKINA, S., KOBAYASHI, T., TAKEUCHI, Y. and YOSHIZAKI, G. (2006). Manipulation of fish germ cell: visualization, cryopreservation and transplantation. J Reprod Dev 52: 685-693.

PELEGRI, F. (2003). Maternal factors in zebrafish development. Dev Dyn228: 535 554.

PELEGRI, F., DEKENS, M.P., SCHULTE-MERKER, S., MAISCHEIN, H.M., WEILER C. and NUSSLEIN-VOLHARD, C. (2004). Identification of recessive maternaleffect mutations in the zebrafish using a gynogenesis-based method. Dev Dyn 231: 324-335.

RYU, S., HOLZSCHUH, J., ERHARDT, S., ETTL, A.K. and DRIEVER, W. (2005) Depletion of minichromosome maintenance protein 5 in the zebrafish retina causes cell-cycle defect and apoptosis. Proc Nat/ Acad Sci USA 102: 18467 18472.

SEKI, S., KOUYA, T., TSUCHIYA, R., VALDEZ, D.M., JR., JIN, B., HARA, T., SAIDA, N., KASAI, M. and EDASHIGE, K. (2008). Development of a reliable in vitro maturation system for zebrafish oocytes. Reproduction 135: 285-292.

SELMAN, K., RA, W., SARKA, A. and X, Q. (1993). Stages of oocyte development in the zebrafish Brachydanio rerio. J Morphology 218: 203-224.

TOKUMOTO, T., TOKUMOTO, M. and NAGAHAMA, Y. (2005). Induction and inhibition of oocyte maturation by EDCs in zebrafish. Reprod Biol Endocrino/3: 69. 


\section{Further Related Reading, published previously in the Int. J. Dev. Biol.}

See our recent Special Issue Epigenetics \& Development edited by Saadi Khochbin and Stefan Nonchev at:

http://www.ijdb.ehu.es/web/contents.php?vol=53\&issue=2-3

Unaltered imprinting establishment of key imprinted genes in mouse oocytes after in vitro follicle culture under variable follicle-stimulating hormone exposure

Ellen Anckaert, Tom Adriaenssens, Sergio Romero, Sarah Dremier and Johan Smitz Int. J. Dev. Biol. (2009) 53: 541 - 548 (doi: 10.1387/ijdb.082619ea)

Maternal-effect loci involved in Drosophila oogenesis and embryogenesis: P elementinduced mutations on the third chromosome

Manolo Bellotto, Daniel Bopp, Kirsten A Senti, Richard Burke, Peter Deak, Peter Maroy, Barry Dickson, Konrad Basler and Ernst Hafen

Int. J. Dev. Biol. (2002) 46: 149-157

Sex reversal of genetic females $(\mathrm{XX})$ induced by the transplantation of $\mathrm{XY}$ somatic cells in the medaka, Oryzias latipes

Al Shinomiya, Naoki Shibata, Mitsuru Sakaizumi and Satoshi Hamaguchi

Int. J. Dev. Biol. (2002) 46: 711-717

Requirement of Drosophila I(2)gl function for survival of the germline cells and organization of the follicle cells in a columnar epithelium during oogenesis C De Lorenzo, D Strand and B M Mechler

Int. J. Dev. Biol. (1999) 43: 207-217

Germ cells and germ cell transplantation

A McLaren

Int. J. Dev. Biol. (1998) 42: 855-860

Endocrine regulation of gametogenesis in fish

Y Nagahama

Int. J. Dev. Biol. (1994) 38: 217-229

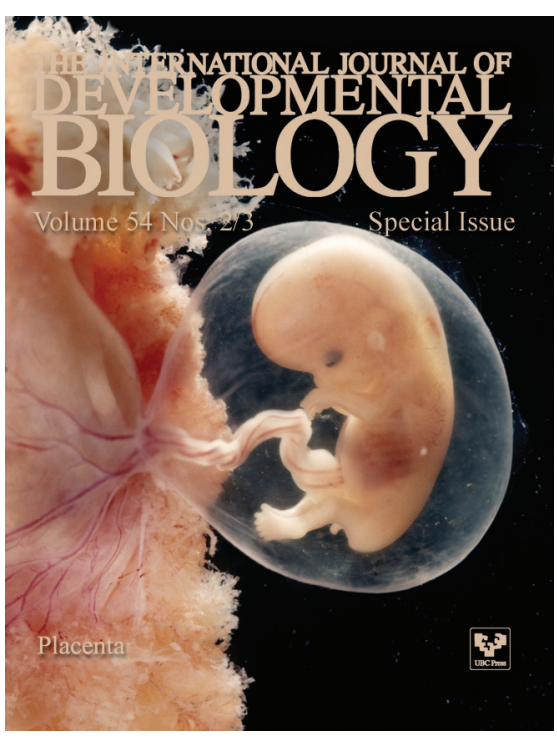

5 yr ISI Impact Factor $(2008)=3.271$

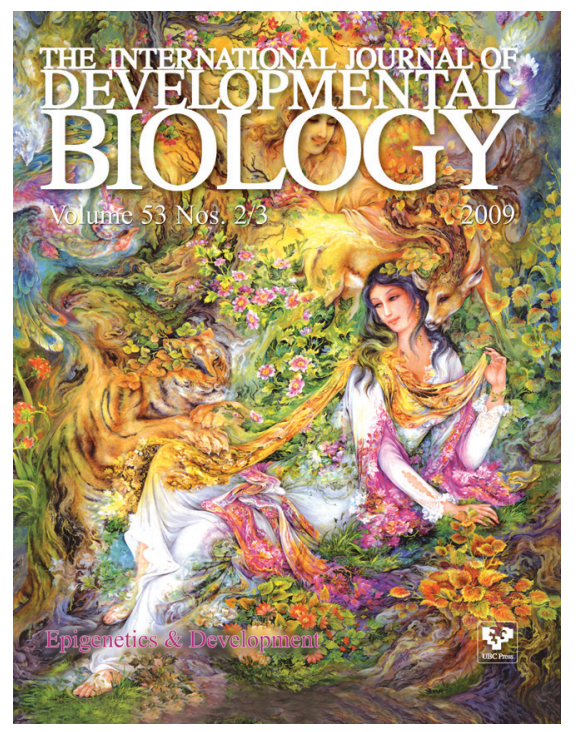

